\title{
Ayur-informatics: Establishing an in-silico-ayurvedic medication for Alzheimer's disease
}

\author{
Mohini Gore*, Preenon Bagchi, Desai N.S. and Ajit Kar \\ Azyme Biosciences Pvt. Ltd., Bangalore-560069, mohinig@gmail.com \\ Padmashree Dr. D.Y. Patil University, Navi Mumbai-400706 \\ Satsang Herbal Research Laboratory, S.R. Mandir, Satsang, Deoghar-814116
}

\begin{abstract}
Alzheimer's disease is an incurable, degenerative, and terminal disease. It is associated with mutations in Amyloid Precursor Protein (APP), Presenilin 1 (PS1), Presenilin 2 (PS2), or Apolipoprotein E (APOE). 3D structures of these 4 proteins were generated using Homology Modeling. Active compounds of medicinal herbs- Canscora decussate, Nardostachys jatamansi and Mucuna pruriens were selected as these three herbs have properties of memory enhancement. Chemical structures of the active component of these herbs were drawn using chemsketch, combined \& converted to *.pdb. The four proteins were successfully docked with Canscora decussate- Nardostachys jatamansi -Mucuna pruriens's active
\end{abstract} component combination.

Keywords- Alzheimer's disease, Ayurveda, Canscora decussate, Nardostachys jatamansi, Mucuna pruriens, Drug designing

\section{Introduction}

Alzheimer's disease (AD) is the most common neurodegenerative disease and the prevalence is increasing with the longer life span of the human population [1]. Alzheimer's Disease International (ADI) estimates that there are currently 30 million people with dementia in the world, with 4.6 million new cases annually (one new case every 7 seconds). The number of people affected will be over 100 million by 2050 [2]. It is the fourth leading cause of death in individuals over age 65 . $A D$ is a progressive neurodegenerative disorder with insidious onset and characterized by severe decline in episodic memory. Instrumental signs include aphasia, apraxia, and agnosia, together with general cognitive symptoms, such as impaired judgment, decision-making, and orientation [3]. Gradually, bodily functions are lost and people with severe AD cannot communicate and are completely dependent on others for their care. Near the end, the person may be in bed most or all of the time as the body shuts down [4]. Neuropathology of AD includes structural Gray Matter (GM) atrophy in temporal, parietal, and frontal cortices, functional changes prominently in the parietal cortex (including the posterior cingulate gyrus and lateral parietotemporal areas), and altered white matter (WM) fiber integrity in parietal, temporal, and frontal cortices [5]. Senile plaques (SP) and neurofibrillary tangles (NFT) have been regarded as the pathological 'hallmarks' of Alzheimer's disease [6]. Amyloid plaques are dense deposits of amyloid-beta $(A \beta)$ protein. Accumulation of aggregated amyloid fibrils, which are believed to be neuro-toxic, causes loss of neurons and synapses in the cerebral cortex and certain subcortical regions and results in gross atrophy of the affected areas [7]. In AD, tau protein becomes hyperphosphorylated and aggregates into Paired Helical Filaments (PHF), the main component of NFTs. Indeed, altered tau protein function has emerged as a key factor in many neurodegenerative diseases, including AD. Hyperphosphorylation of tau protein is thought to lead to microtubule instability, neurofibrillary tangle formation, and loss of a functional microtubule cytoskeleton, contributing to neuronal cell dysfunction and cell death [8]. Familial early onset forms of $A D$ are associated with mutations either in the precursor protein for $A \beta$ (the $\beta$-amyloid precursor protein, APP, on chromosome 21q21) or in presenilin-1 (PS1, on chromosome 14q24.3) or presenilin-2 (PS2, on chromosome 1q31-q42) [9]. Either PS1 or PS2 can be the catalytic subunit of $\gamma$-secretase, which is the final endoprotease in the pathway that generates the peptide [10]. The connection between Apolipoprotein $E(A p o E)$ and $A D$ is well established [11]. The gene for apolipoprotein $E$ is located on chromosome 19q13.2 [12]. Herbal medicine has been used in India for thousands of years and is increasingly been used worldwide during the last few decades [13] Ayurveda is being seen as a rich resource for new drug development by modern day pharmacologists [14]. Shankhpushpi (Canscora decussate) is considered as Medhya Rasayana in Ayurvedic texts. Shankhpushpi is an Ayurvedic drug used for its action on the central nervous system, especially for boosting memory and improving intellect. Canscora decussate finds its use for its therapeutic effects on CNS disorders like insanity, epilepsy, nervous debility and memory enhancement [15]. Nardostachys jatamansi is one of the medhya resayanas - brain tonics, useful in enhancing the memory $[16,17,18]$. The cholinergic hypothesis of Alzheimer's disease (AD) has provided the rationale for the current pharmaco-therapy of this disease, in an attempt to reduce the cognitive decline caused by cholinergic deficits. There have been studies which show that Nardostachys jatamansi exhibits 
inhibition of acetylcholinesterase [16, 17]. Powdered seeds of Kavacha (Mucuna pruriens) are known to possess many medicinal properties and cure many ailments such as nervous disorders, diarrhea, Parkinson's disease etc. It is also known to have memory enhancement properties [19, 22] and is used as a nervine tonic $[19,20]$. Active component of Canscora decussate, xanthone [15], Nardostachys jatamansi, nardal [21] and Mucuna pruriens ergotamine [22] are utilized in this work. Drug discovery has evolved through various stages into more rational and evidence-based drug designing. Structure-based drug designing has made tremendous contributions in the field of cancer chemotherapy, drug resistant infections, and neurological diseases, to mention a few. New drug discovery methods are furthered by developments in the technology especially computers, bioassay techniques and calibrated instruments. Computational structure-based drug designing opens the door to novel treatments in modern medicine [23].

\section{Methodology}

Softwares/Web Servers used

- modeller9v7

- $\quad$ Swiss-PdbViewer v4.01

- 3)ACD/ChemSketch Freeware, version 11.00.

- 4)RAMPAGE

- 5)ArgusLab 4.0.1

- 6)HEX 5.1

- 7)PATCHDOCK

Alzheimer's disease causing proteins- APP, APOE, Presenilin 1 and Presenilin 2 were taken for this work. Human APP protein with accession no- AAA51722.1, APOE with accession noP02649.1, Presenilin 1 with accession noP49768.1, and Presenilin 2 with accession noP49810.1 were taken from NCBl's entrez database. Homology modeling was carried out using Modeller 9v7, for predicting $3 \mathrm{D}$ structures for the above mentioned proteins. Homology modeling was done using Modeller 9v7; templates used for it were homologous protein structures from RCBS PDB database. The following templates were used-

APP- 1 owtA (identity $=97 \%$, source Homo sapiens - information taken from Interpro via Hhpred search), 1rw6A (identity $=99 \%$, source- Homo sapiens information taken from Hhpred search), $3 \mathrm{k} 66 \mathrm{~A}$ (identity $=33 \%$, source- Caenorhabditis elegans information taken from Hhpred search).

APOE- 1gs9A, (identity $=99 \%$, source- Homo sapiens information taken from Hhpred search), 1ya9A (identity $=37 \%$, source-Mus musculusinformation taken from Interpro via Hhpred search), 1 nfnA (identity $=19 \%$, source-Homo sapiens information taken from Hhpred search)
Presenilin 1- 3dhwA (identity $=67 \%$, sourceEscherichia coli - information taken from Interpro via Hhpred search), 1yo8A (identity $=67 \%$, source- Streptococcus pyogenes - information taken from Interpro via Hhpred search), 2ap3A (identity $=23 \%$, source- Staphylococcus aureusinformation taken from Interpro via Hhpred search)

Presenilin 2- 2iw3A (identity $=18 \%$, sourceSaccharomyces cerevisiae - information taken from Interpro via Hhpred search), 2p4qA (identity $=21 \%$, source- Saccharomyces cerevisiae- information taken from Hhpred search), 1 su $4 \mathrm{~A}$ (identity $=23.6 \%$ Source: Oryctolagus cuniculus- information taken from Hhpred search)

5 models of each of the above proteins were generated. The models were analyzed by Rampage Ramchandran plot server and the best model of each was selected.

Chemical structures of active component of Nardostachys jatamansi, nardal, active component of Canscora decussate, xanthone and active component of Mucuna pruriens, ergotamine were drawn and combined using ACD chemsketch software. This combination structure was saved as *.mol file and was later converted to *.pdb file using Argus lab software.



Fig. 1-Chemical structure of nardal<smiles>CN1c2ccccc2CC(C(=O)NC2(C)CC3C(=O)N4CCCC4C(O)(C2)N3C)/C=C2/c3cccc4[nH]cc(c34)CC21</smiles>

Fig. 2- Chemical structure of ergotamine<smiles>CCc1c(OC)c(OC)cc2oc3cc(OC)cc(O)c3c(=O)c12</smiles>

Fig. 3- Chemical structure of xanthone 


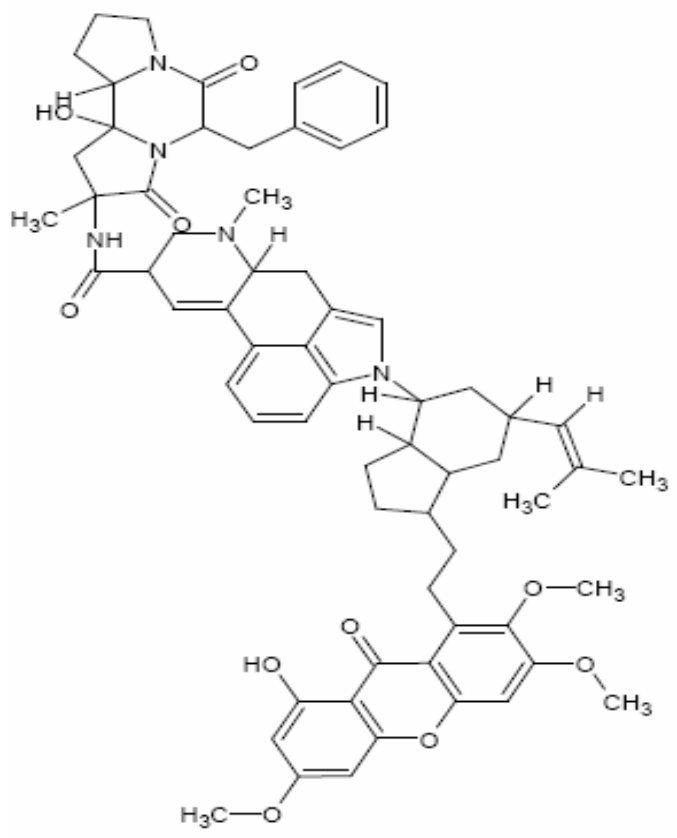

Fig. 4- Combined Structure of nardal, ergotamine \& xanthone

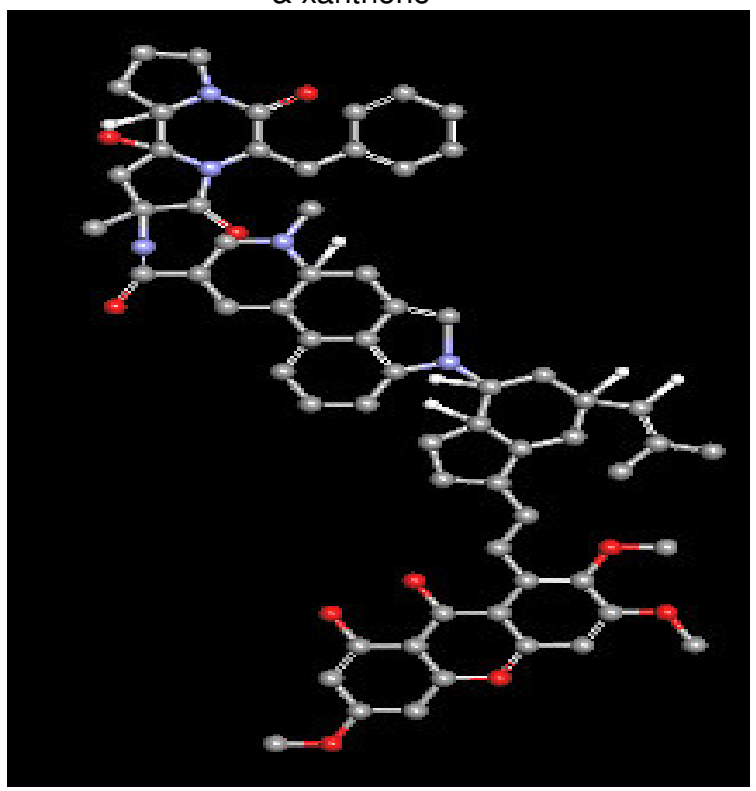

Fig. 5- Combined Structure of nardal, ergotamine \& xanthone in Argus lab

Each of the proteins used for this work, namely APP, APOE, PS1 and PS2 was successfully docked with Nardostachys jatamansi- Canscora decussate Mucuna pruriens's active component, i.e., nardal, ergotamine \& xanthone combination.

\section{Result}

3D structure of APP obtained by homology modeling was analyzed by Rampage Ramchandran plot server. The results obtained for best model (\#5) are as follows:
Number of residues in favoured region( $98.0 \%$ expected): 381 (92.9\%)

Number of residues in allowed region( $2.0 \%$ expected): $22(5.4 \%)$

Number of residues in outlier region : $7(1.7 \%)$

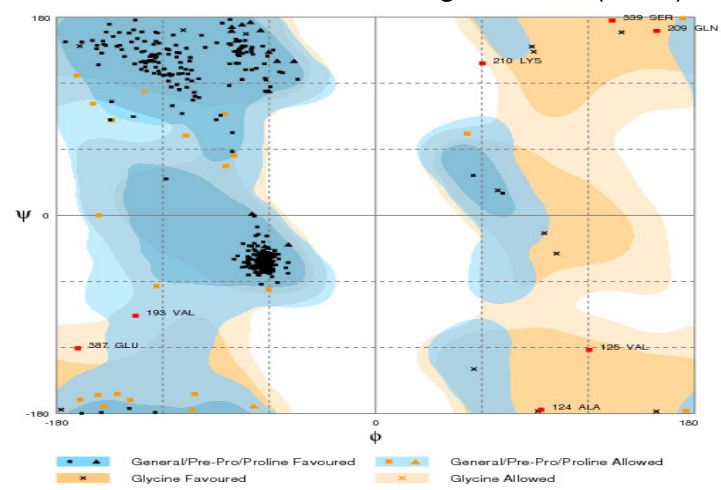

Fig. 6- Ramachandran Plot analysis APP.pdb (model 5)

The 3D structure of APOE obtained by homology modeling was analyzed by Rampage Ramchandran plot server. The results obtained for best model (\#2) are as follows:

Number of residues in favoured region ( 98.0\% expected): 302 (95.9\%)

Number of residues in allowed region ( 2.0\% expected): $10(3.2 \%)$

Number of residues in outlier region : $3(1.0 \%)$

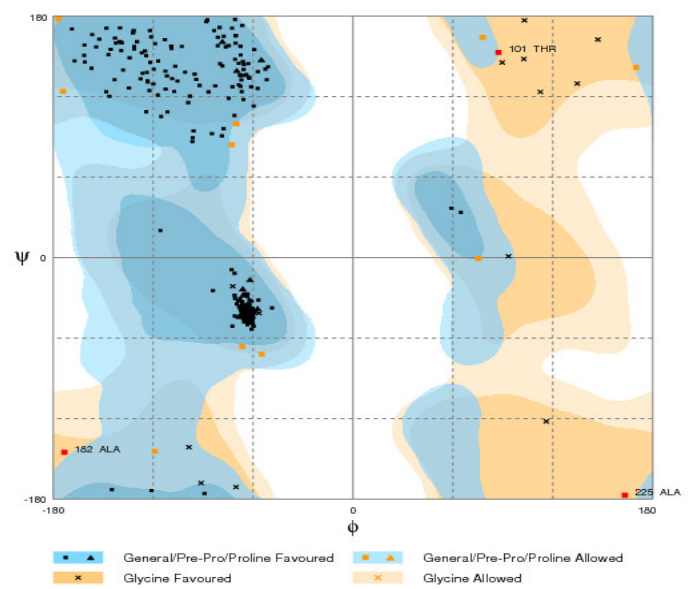

Fig. 7- Ramachandran Plot analysis APOE.pdb (model 2)

The 3D structure of Presenilin1 obtained by homology modeling was analyzed by Rampage Ramchandran plot server. The results obtained for best model (\#2) are as follows:

Number of residues in favoured region( $98.0 \%$ expected): 397 (85.4\%)

Number of residues in allowed region $(\sim 2.0 \%$ expected): 47 (10.1\%)

Number of residues in outlier region : 21 (4.5\%) 


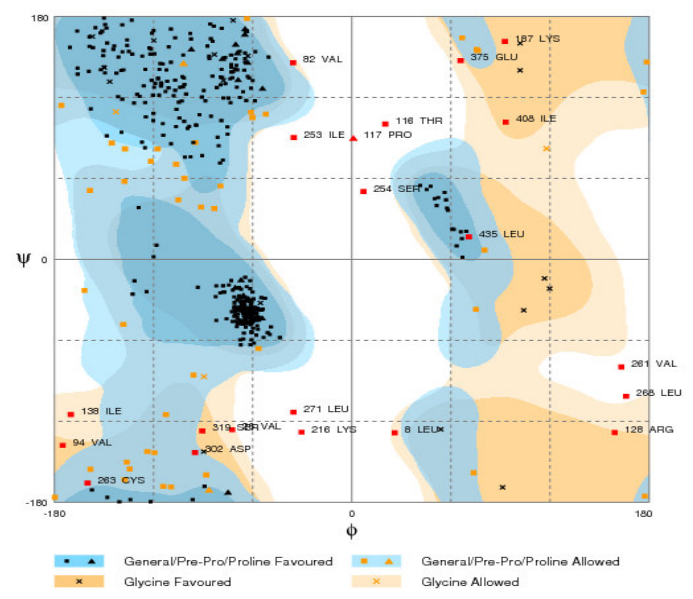

Fig. 8- Ramachandran Plot analysis PS1.pdb (model 2)

The 3D structure of Presenilin2 obtained by homology modeling was analyzed by Rampage Ramchandran plot server. The results obtained for best model (\#2) are as follows:

Number of residues in favoured region ( 98.0\% expected): 390 (87.4\%)

Number of residues in allowed region $(\sim 2.0 \%$ expected): 44 (9.9\%)

Number of residues in outlier region : 12 $(2.7 \%)$

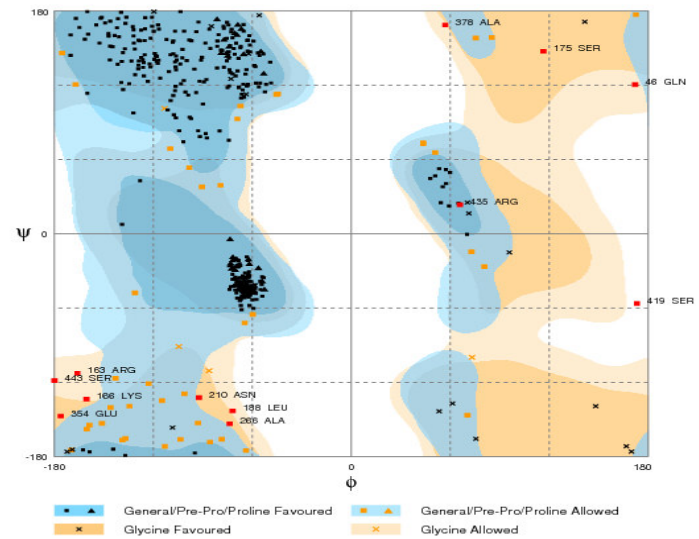

Fig. 9- Ramachandran Plot analysis PS2.pdb (model 2)

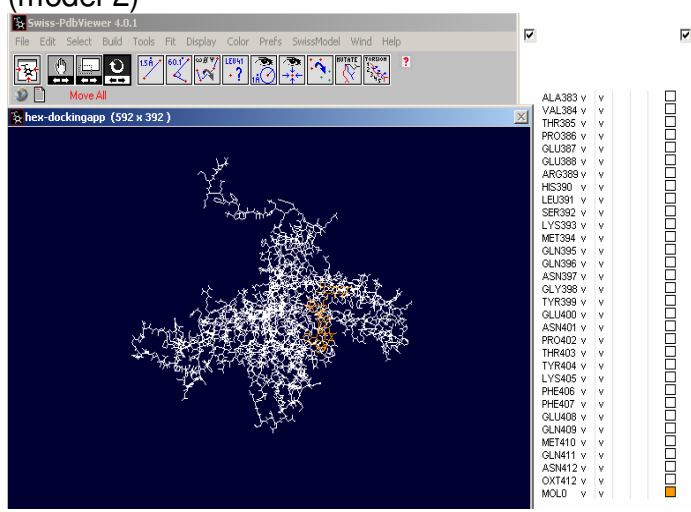

Fig. 10- Docked structure APP with nardal, ergotamine \& xanthone combination

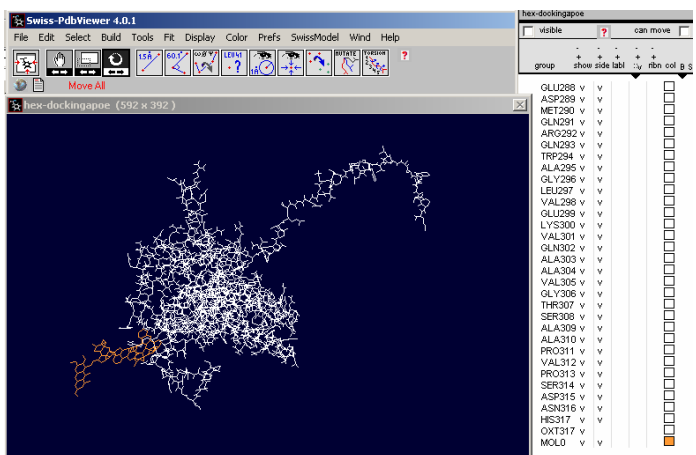

Fig. 11- Docked structure APOE with nardal, ergotamine \& xanthone combination

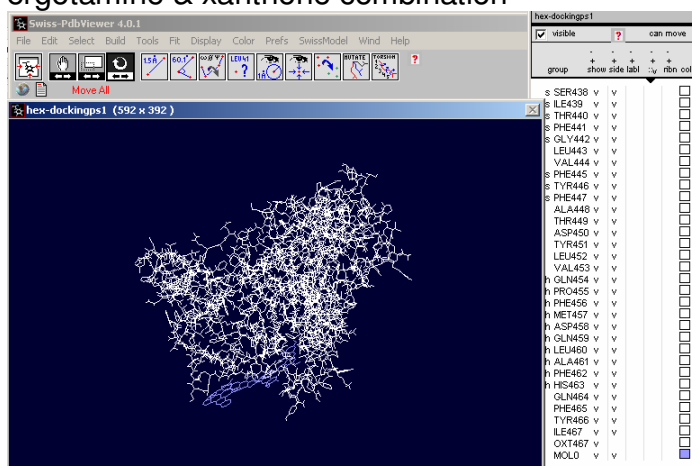

Fig. 12- Docked structure PS1 with nardal, ergotamine \& xanthone combination

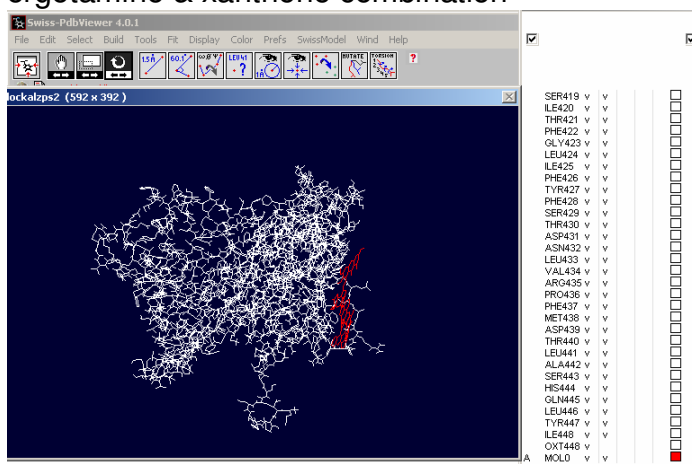

Fig. 13- Docked structure PS2 with nardal, ergotamine \& xanthone combination

\section{Conclusion}

The successful docking of APP, APOE, PS1, PS2 with nardal, ergotamine \& xanthone combination proves that the combination can be effective in the treatment of Alzheimer's disease. Again, docking scores as per patch dock server are- APP- 10528, APOE- 11062, PS1- 10592 and PS2- 10264.

\section{Discussion}

This in-silico-herbal work makes use of ayurvedic herbs in Computer Aided Drug Designing. The principle outlined in Homology Modelling is used to model the 3D structure of the proteins APP, APOE, PS1, \& PS2. Since suitable template was not found by searching across pdb_95.pir and BLAST search, so the authors have used 
HHPred search engine to determine appropriate templates and used them to model the proteins. The mention of herbs Canscora decussate, Nardostachys jatamansi and Mucuna pruriens is found in the works of Maharshi Charaka as memory enhances as they are found to have brain \& CNS regenerative property. Henceforth the authors utilize the combination of the active components of the herbs Canscora decussate, Nardostachys jatamansi and Mucuna pruriens for docking with the proteins of Alzheimer's disease. Again, since the work is done in in-silico platform, the combination (nardal, ergotamine \& xanthone combination) needs to go to clinical testing to establish its efficacy.

\section{References}

[1] Frykman S., Hur J.Y., Frånberg J., Aoki M., Winblad B., Nahalkova J., Behbahani $\mathrm{H}$. and Tjernberg L.O. (2010) PLoS One, 5(1), e8948.

[2] Cleusa P Ferri., Martin Prince., Carol Brayne., Henry Brodaty., Laura Fratiglioni., Mary Ganguli., Kathleen Hall., Kazuo Hasegawa., Hugh Hendrie., Yueqin Huang., Anthony Jorm., Colin Mathers., Paulo R Menezes., Elizabeth Rimmer. and Marcia Scazufca. (2005) The Lancet, 366 (9503), 2112 - 2117.

[3] Rachel Mistur., Lisa Mosconi., Susan De Santi., Marla Guzman., Yi Li, Wai Tsui., Mony J. de Leon. and EdDab. (2009) $J$ Clin Neurol, 5(4), 153-166.

[4] Alzheimer's Disease Fact Sheet, National Institute on Aging. (2008) $\mathrm{NIH}$ Publication No. 08-6423.

[5] Tosun D., Schuff N. and Weiner M. (2009) Conf Proc IEEE Eng Med Biol Soc, 1(698), 1-4.

[6] Armstrong R.A. (2009) Folia Neuropathol, 47(4), 289-99.

[7] Fu L.M., Li J.T. (2009) Evid Based Complement Alternat Med.

[8] Azorsa D.O., Robeson R.H., Frost D., Hoovet B.M., Brautigam G.R., Dickey C., Beaudry C., Basu G.D., Holz D.R., Hernandez J.A., Bisanz K.M., Gwinn L., Grover A., Rogers J., Reiman E.M., Hutton M., Stephan D.A., Mousses S. and Dunckley T. (2010) BMC Genomics, 11(25), 1-10.

[9] Kaj Blennow., Mony J de Leon Ed.D. and Henrik Zetterberg. (2006) The Lancet, 368 (9533), 387-403.

[10] Murphy M.P., LeVine H 3rd. (2010) J Alzheimers Dis, 19(1), 311-23.

[11] Luo J., Maréchal J.D., Wärmländer S., Gräslund A. and Perálvarez-Marín A. (2010) PLoS Comput Biol, 6(2), e1000663.

[12] Ekaterina Rogaeva. (2008) Geriatrics and Aging, 11(10), 577-581.
[13] Aneesh T.P., Hisham M., Sekhar M.S., Madhu M. and Deepa T.V. (2009) Int J Green Pharm, 3(3), 184-190.

[14] Patwardhan K., Gehlot S., Singh G. and Rathore H. (2010) Int J Ayurveda Res, 1(1) , 49-54.

[15] Sethiya N.K., Nahata A., Mishra S.H. and Dixit V.K. (2009) J Chin Integr Med / Zhong Xi Yi Jie He Xue Bao, 7(11), 1001-1022.

[16] Mukherjee P.K., Kumar V. and Houghton P. (2007) J. Phytother Res, 21(12), 1142-5.

[17] Vinutha B., Prashanth D., Salma K., Sreeja S.L., Pratiti D., Padmaja R., Radhika S., Amit A., Venkateshwarlu K. and Deepak M. (2007) J Ethnopharmacol, 109(2), 359-63.

[18] Samy R.P., Pushparaj P.N. and Gopalakrishnakone P. (2008) Bioinformation, 3(3), 100-10.

[19] Poornachandra M.N., Khanam Salma., Shivananda B.G., Shivananda T.N. and Dris R.(2005) International journal of food, agriculture and environment, 33(4), 13-15.

[20] Misra L. and Wagner H. (2007) Indian $J$ Biochem Biophys, 44(1), 56-60.

[21] Venkateshwara Rao G., Annamalai T. and Mukhopadhyay T. (2008) Indian J Chem, 47B (1), 163-165.

[22] Peter J. Houghton. and Melanie-Jayne Howes. (2005) Neurosignals, 14(1-2), 622.

[23] Vijayakrishnan R. (2009) J Postgrad Med, 55(4), 301-304. 